\title{
Excitation Contraction Coupling in Hypertrophy and Failing Heart Cells
}

\author{
Yiqiu Zhou ${ }^{1}$ \\ ${ }^{1}$ High school, Ulink College, Guangzhou, China
}

\begin{abstract}
The contraction of the heart is dependent on a process named the excitation-contraction coupling (E-C coupling). In hypertrophy and failing heart models, the expression, phosphorylation and function of key calcium handling proteins involved in E-C coupling are altered. It's important to figure out the relationship changes between calcium channel activity and calcium release from sarcoplasmic reticulum (SR). This review will therefore focus on novel components of E-C coupling dysfunction in hypertrophy and failing heart, such as L-type Ca2+ channel (LCC), ryanodine receptor type-2 channel (RyR2) and SR Ca ATPase (SERCA), and how these molecular modifications altered excitation-contraction coupling. A lot of literature was well read and sorted. Recent findings in E-C coupling during hypertrophy and heart failure were focused on. Most importantly, the electrophysiological and signal pathway data was carefully analyzed. This review summarizes key principles and highlights novel aspects of E-C coupling changes during hypertrophy and heart failure models. Although LCC activity changed little, the loss of notch in action potential, reduced $\mathrm{Ca} 2+$ transient amplitude and desynchronized $\mathrm{Ca} 2+$ sparks resulted in a decreased contraction strength in hypertrophy and heart failure models. What's more, L-type Ca2+ current becomes ineffective in triggering RyR2 Ca2+ release from SR and the SR uptake is reduced in some models. It has great meanings in understanding the E-C coupling changes during different heart diseases. Theses novel changes suggest potential therapeutic approaches for certain types of hypertrophy and heart failure.
\end{abstract}

\section{Introduction}

As we all knew, heart is one of the most important organs in our body. The weighted of a human heart is around $300 \mathrm{~g}$ and it is about the size of a fist. The main function of heart is pumping blood to the whole body and it is a bag made of muscle cells called the cardiac muscle. The cardiac muscle is not like other muscle cells in body cause it is myogenic [1]. It can naturally contract and relax by its own and no need to receive an impulse from the nerve system to start working. Theoretically speaking, if the heart is putting in an environment which is warm, oxygenated and nutrients are abundant, it is able to beat rhythmically. However, the individual heart cell cannot contract under its own natural rhythms, the whole heart should follow the rules of the cardiac cycle [2]. If the cardiac cycle is disordered then the heart will lose the ability to work as a pump. The cycle starting from a muscle wall from right atrium called the sinoatrial node. It contracts each time faster than other parts in the heart and sets up an electrical excitation wave which can spread efficiently through the whole atrial walls. Then the rest of the cardiac muscle responses to this wave and the whole atria contracts. The excitation wave sweeps onwards and reaches the atrioventricular node which is another patch of the cells to delay the impulse and let it travels down to the ventricle. The electrical wave is now on the septum of the heart along fibers named Purkinje tissue. When it reaches to the bottom of the heart, it turns upwards to let the whole cardiac muscle in ventricle wall contracts. This is the whole journey of the electrical excitation wave going through the muscle in our heart.

To further understand the relationship between the electrical wave and the contraction of the muscle in the heart, scientists focus on the E-C coupling and its property changes in hypertrophy and heart failure.

E-C coupling refers to the process by which cardiac myocyte translates electrical excitation into mechanical contraction and $\mathrm{Ca}^{2+}$ plays a crucial role during it [3]. The SR is the source for most of the $\mathrm{Ca}^{2+}$ and it is released by the process known as the calcium-induced calcium release. $\mathrm{Ca}^{2+}$ binds to the troponin and triggers the sliding of the thin and thick filaments, shortening the sarcomere [4]. Normally the heart requirs to maintain its function by controlling the level of the intercellular $\mathrm{Ca}^{2+}$, high in the systole and low in the diastole. For example, in the process of ventricular systole, the level of $\mathrm{Ca}^{2+}$ increases and filaments slip to cause muscular wall contracts. The atrioventricular valves are pushing shut to avoid blood flowing backwards and causes the pressure to pump blood out of the heart. To put it simply, depending on the number of successfully combined $\mathrm{Ca}^{2+}$ with troponin and also their binding strength, the force that forces heart to pump will increase as the number increases.

\footnotetext{
* Corresponding author: zyq20021103@icloud.com
} 
To be precisely on processing the intercellular $\mathrm{Ca}^{2+}$ cycling, the relationship between various channels and pumps should be included. So scientist started to consider it into two parts, the structural coupling and the functional coupling [3]: (1) structural coupling: all the transporters within the dyad link the SR and transverse tubule (TT) together, this will create the shortest approach for $\mathrm{Ca}^{2+}$ to release. (2) functional coupling: to balance the amount of influx and efflux $\mathrm{Ca}^{2+}$ across every membrane stay the same and under steady state in every beats. The whole process will be optimized by not only the combination of different $\mathrm{Ca}^{2+}$ channels and transporters, but also their strict location and spatial positioning.

Different heart diseases models have given useful insight into the E-C coupling changes. Failing E-C coupling could come from altered properties and interactions among $\mathrm{Ca}^{2+}$ channels. Specifically on the expression, phosphorylation and function changes. To figure out the problem we have sorted and analyzed the electrophysiological and signal pathway data in different hypertrophy and heart failure models. The changed action potential timecourse, LCC activity, RyR included signal pathway and SR calcium load and uptake are all discussed. Much research in this filed focused on the pathomechanisms involved in hypertrophy and heart failure may develop targeted therapeutic approaches for patients with heart failure.

\section{The novel components of E-C coupling dysfunction in hypertrophy and failing heart}

\subsection{Myocardial function in heart failure}

E-C coupling is related to the close association between the SR network and the TT membranes. The L-type $\mathrm{Ca}^{2+}$ channels located in TT membrane will be stimulated by the action potential depolarization and caused the resulting entry of small amount of $\mathrm{Ca}$, which will trigger a large amount of $\mathrm{Ca}^{2+}$ increased in the dyadic space (an area surrounded by the SR and the TT). This process mentioned above is called the calcium-induced calcium release. The process should be given under the basis of the closed connection between the junctional SR and the t-tubules membrane, so the RyR2 can be closer to the Ltype $\mathrm{Ca}^{2+}$ channels (from the t-tubules) $[5,6]$, nearly approximated to $15 \mathrm{~nm}$ [7], forming the cardiac dyad which is the basic principle of starting the ventricle systole upon $\mathrm{Ca}^{2+}$ transient. After the $\mathrm{Ca}^{2+}$ releases into the cytosol, the increase of $\mathrm{Ca}^{2+}$ needs to be remove out as the resting state. If it is unbalanced, then it will transiently occur in the dyad causing the changes of the $\mathrm{Ca}$ transient and disordering the frequency of amplitude or pausing stimulation. If the stimulation is finding stop in the ventricular muscle, the $\mathrm{Ca}^{2+}$ will leak out from the SR [8] and make its content low. To let the $\mathrm{Ca}^{2+}$ transient back into the resting sate, $\mathrm{SR} \mathrm{Ca}^{2+}$ content increases. This will ensure the Ca efflux finally balances the influx and back in a steady state $[9,10]$. This balance theory is not only suitable for the surface membrane but also applied to organelles such as mitochondria.

In hypertrophy and heart failure the mass of heart increased. Hypertrophy can divided into two kinds (Figure 1): (1) physiological cardiac hypertrophy: normally it's known as the 'athlete's heart'. The cause of this hypertrophy is because of the standing exercise training and it is reversible. No fibrosis or apoptosis is apparent and given as normal cardiac morphology or even enhanced cardiac function. (2) pathological cardiac hypertrophy: it is usually accompanied by an increase in interstitial fibrosis and massive cell death leading to cardiac dysfunction [11]. The most obvious pathologic feature is lowering the times and speed of contraction and relaxation, which can be easily found in ventricular myocytes from a failing human hearts [12]. This change is graded in terms of different degree of cardiac insufficiency and is associated with impaired $\mathrm{Ca}^{2+}$ processing. In dilated human cardiomyopathy, diastolic $\mathrm{Ca}^{2+}$ transients are prolonged due to a reduced ability to restore low resting $\mathrm{Ca}^{2+}$ levels. Therefore, increased resting or end-diastolic $\mathrm{Ca}^{2+}$ can lead to $\mathrm{Ca}^{2+}$ overload. Dysfunction of $\mathrm{Ca}^{2+}$ removal from cytosol is an early manifestation of pressure overload hypertrophy, which impairs cardiac diastolic function [13].

\subsection{Triggers of calcium release :T-type $\mathrm{Ca}^{2+}$ current (ICaT) and L-type $\mathrm{Ca}^{2+}$ current (ICaL)}

In cardiac cells we can only discover two types of ICa which are L- and T-type Ica. [14, 15]. T-type $\mathrm{Ca}^{2+}$ channels have been found in a variety of excitatory and non-excitatory cells [16], and they may represent a heterogeneous subgroup of $\mathrm{Ca}^{2+}$ channels with significant differences in functional properties [17]. While the cardiac L-type $\mathrm{Ca}^{2+}$ channels is known as the site of operating ICaL and it is a trigger for $\mathrm{Ca}^{2+}$ to release and refill into the $\mathrm{SR}$ again which play a crucial role in the E-C coupling [18]. These two channels shared similar name but with distinct electrophysiological and pharmacological properties. During the voltage-clamp depolarisation testing, ICaT is characterized by rapid decay and slow inactivation rate, while ICaL lasts longer and has a faster inactivation rate. The T- and L- channels can also distinguished by the threshold of activation and their voltage-dependence of availability for opening. Usually ICaL is strong-voltage-activated whereas ICaT is activated by low depolarizations, for example ICaL needled at depolarization $\geq-30 \mathrm{mV}$ but ICaT stimulated in a more negative result around $-60 \mathrm{mV}$ [18]. However scientists still don't know well about the T-type $\mathrm{Ca}^{2+}$ channels so here will directly talk about its expression in diseased heart cells. In addition to a possible contribution to the automaticity of adult heart tissue, ICaT appears to be associated with hypertrophy. When isolated from a normal adult feline left ventricle, the presence of ICaT was completely undetectable in longterm conditions of pressure-induced ventricular hypertrophy [19]. Similar case, a genetically determined cardiac myopathic Syrian hamster suffered an ascensive 
and ultimately fatal congestive HF. Its ICaT had a 2 to 3 fold higher density than in a normal heart cells but its ICaL remain unchanged and this caused the inactivation kinetics [20]. All these changes suggest that ICaT is involved in the pathogenesis of $\mathrm{Ca} 2+$ overload and cardiomyopathy arrhythmia.

On the other hand, about the L-type $\mathrm{Ca} 2+$ channels scientists obtained many groups of various animals modules and tried to find out the different changes of ICaL in HF [21-28]. In addition to species dependence, there are many reasons for the obvious heterogeneity of model differences, the importance of hypertrophy, the degree of hemodynamic pressure and the stage of heart failure. There may also be varying degrees of hypertrophy or failure between cells in the same heart tissue. But the overall trend has been found out not affected by $\mathrm{HF}$ at all. Obviously, it has no significant effect on the electrophysiological properties of ICaL.

The deterioration of calcium induced calcium release process in hypertrophy/heart failure is thought to be the principal cause of the pump dysfunction. In heart failure non-uniform release of $\mathrm{Ca}^{2+}$ sparks will lead to a slower rate of rise of the $\mathrm{Ca}^{2+}$ transient which will probably cause disordered binding of $\mathrm{Ca}^{2+}$ to troponin $\mathrm{C}$ and slower myocyte contraction [29, 30]. (Figure 2A) The reduction of ventricular myocyte contractility in the hypertrophied/failing is closely correlated with the abnormal $\mathrm{Ca}^{2+}$ homeostasis. The cellular basis defects in excitation-contraction coupling, $\mathrm{Ca}^{2+}$ release and uptake events are all considered.

At the cellular level, the contractile power during E$\mathrm{C}$ coupling is governed by a mechanism known as calcium induced calcium release [31]. In this process, $\mathrm{Ca}^{2+}$ influx through L-type $\mathrm{Ca}^{2+}$ channels on the cell surface membrane (including TT) activates ryanodine receptor $\mathrm{Ca}^{2+}$ release from the SR to generate cell-wide $\mathrm{Ca}^{2+}$ transients [32]. Besides L-type $\mathrm{Ca}^{2+}$ channels and RyR2, $\mathrm{Ca}^{2+}$ cycling proteins, e.g., sarcoplasmic reticulum $\mathrm{Ca}^{2+}$ pumps, $\mathrm{N}_{\mathrm{a}}^{+}-\mathrm{Ca}^{2+}$ exchangers, and their regulatory mechanisms, are also important in determining the amplitude and kinetics of $\mathrm{Ca}^{2+}$ transients [32]. All these mechanisms have been studied in a wide variety of hypertrophy and heart failure models [32] [33, 34]. Most studies support the idea that the L-type $\mathrm{Ca}^{2+}$ channel activity does not change much during hypertrophy and heart failure. However, the $\mathrm{Ca}^{2+}$ transients triggered by comparable L-type $\mathrm{Ca}^{2+}$ channel currents are decreased in amplitude and/or slowed in kinetics in most models of decompensated hypertrophy (DHT) and heart failure [26] (Figure 2B). These studies lead to the notion that the $\mathrm{Ca} 2+$ influx through L-type $\mathrm{Ca} 2+$ channels becomes less effective in triggering RyR2 Ca release [26].

A study recently using the patch-clamp methods under the confocal microscopy showed that although $\mathrm{ICaL}$ density and $\mathrm{SR} \mathrm{Ca}^{2+}$ release channels are normal in experimental rat models of hypertension induced cardiac hypertrophy and $\mathrm{HF}$, but the $\mathrm{Ca}^{2+}$ channel fails to activate SR $\mathrm{Ca}^{2+}$ release [26]. This experiments support the idea that $\mathrm{Ca}^{2+}$ signaling between the surface membrane and the SR is abnormal in heart failure which means that calcium current of L-type $\mathrm{Ca}^{2+}$ channel is a less effective trigger of $\mathrm{SR} \mathrm{Ca}^{2+}$ release in hypertrophied and failing myocytes [26]. The decreased excitationcontraction coupling gain could be rescued by exposure to $\beta$-agonists in hypertrophied but not failing myocytes, and experiments support that the reduced size of the $\mathrm{Ca}^{2+}$ transition in failing rat myocytes results from a decrease in the $\mathrm{SR} \mathrm{Ca}^{2+}$ release rather than a reduction in $\mathrm{SR} \mathrm{Ca}^{2+}$ loading as show in failing human ventricular myocytes. Meanwhile, other studies found that $\mathrm{SR} \mathrm{Ca}^{2+}$ loading is decreased. SR $\mathrm{Ca}^{2+}$ loading is decreased in the failing myocytes. The density and location of $\mathrm{Ca}^{2+}$ regulatory proteins are changed between the non-failing and failing myocytes. The mainly reason for lower peak systolic calcium current of the early action potential plateau phase in the failing myocyte is that $\mathrm{SR} \mathrm{Ca}^{2+}$ release is smaller and $\mathrm{Ca}^{2+}$ efflux through the forward-mode $\mathrm{N}_{\mathrm{a}}^{+}$$\mathrm{Ca}^{2+}$ exchangers is bigger than normal. Defective excitation-contraction coupling can also reduce the SR $\mathrm{Ca}^{2+}$ release in the failing myocyte. While during the late phase of the action potential plateau calcium current is bigger in the failing myocyte which is mainly caused by the prolonged action potential duration triggers reversemode $\mathrm{Na}^{+}-\mathrm{Ca}^{2+}$ exchangers and reduced SR uptake. Fully recovery of diastolic $\mathrm{Ca}^{2+}$ in failing myocytes need the repolarization of the membrane potential.

\subsection{Other putative triggers of $\mathrm{Ca}^{2+}$ release}

Defects in excitation-contraction coupling gain can't totally explain the fact that $\mathrm{Ca}^{2+}$ transient in failing human myocytes only become significantly different compared to the control group when the heart rate increases in some disease models, so a more likely contributors to the associated reduction in $\mathrm{SR} \mathrm{Ca}^{2+}$ release in failing human myocytes is mainly caused by a frequency-dependent decrease in the size of calcium current of L-type $\mathrm{Ca}^{2+}$ channel and abnormal $\mathrm{SR} \mathrm{Ca}{ }^{2+}$ loading [35-37] (Figure 3). Recent studies suggest that RyR2 phosphorylation level in human heart failure is abnormal which can change the open probability of the calcium release channel. It is solid to say that in hypertrophic and heart failure, the function of the RyR2 is abnormal.

RyR2 is disordered with the increased $\mathrm{Ca}^{2+}$ leak from $\mathrm{SR}$, causing the reduction of $\mathrm{Ca}^{2+}$ content in SR in heart failure (Figure 4) [38, 39]. RyR2 is proposed to be regulated by both protein kinases protein kinase $\mathrm{A}, \mathrm{Ca}^{2+}$ calmodulin-dependent kinase II, protein phosphatase PP1 and PP2A [40, 41].

These results proved that $\mathrm{SR} \mathrm{Ca}^{2+}$ leak threshold is lowered in heart failure. The increase $\mathrm{Ca}^{2+}$ leak from SR in heart failure is caused by altered RyR2 gating properties, which is proposed to be regulated by hyperphosphorylation from cAMP-dependent protein kinase A [42, 43], CaMK [44-47] and dephosphorylation from PP1 $[42,48]$. In heart failure the function of RyR2 undergoes obvious changes. Usually the RyR2 is closed in diastole and allow $\mathrm{Ca}^{2+}$ remain stayed in SR. However in heart failure, the probability of this channel open increased and caused a strong increase in spontaneous and asynchronous Diastolic $\mathrm{Ca}^{2+}$ release events from the 
$\mathrm{SR}$, measured as the $\mathrm{Ca}^{2+}$ spark. One $\mathrm{Ca}^{2+}$ spark can generate by a cluster of four RyR2, together forming a $\mathrm{Ca}^{2+}$ releasing unit [49]. In addition, it has been observed that the release of $\mathrm{Ca}^{2+}$ from SR is not synchronized in time in heart failure, which may be related to the release of a certain amount of $\mathrm{Ca}^{2+}$ ions, resulting in a decrease in contractility [50]. $\mathrm{Ca}^{2+}$ waves can be observed in cardiomyocytes, [51] that is, a spontaneous increase in cytoplasmic $\mathrm{Ca}^{2+}$. Spread throughout the cell. Although it has been proven that they are caused by $\mathrm{Ca}^{2+}$ sparks, the threshold $\mathrm{SR} \mathrm{Ca}^{2+}$ content required to initiate them has been discussed [51]. Moreover, although a method of propagating $\mathrm{Ca}^{2+}$ waves through $\mathrm{Ca}^{2+}$ sparks has also been proposed, there is a differential activation of $\mathrm{Ca}^{2+}$ dependent ion channels [52]. What is important is that, in any case, another important aspect that disrupts the function of RyR2 is the instantaneous inward current (ITI) generated by the power supply NCX due to the RyR2 $\mathrm{Ca}^{2+}$ flux extruded by the exchange with $\mathrm{Na}^{+}$. By inducing delayed depolarization (DAD), these can trigger arrhythmia and sudden cardiac death [49, 53], and appear to be involved in atrial fibrillation [54, 55].

Some researchers believe protein kinase A hyperphospholation on RyR2 leads to increased $\mathrm{Ca}^{2+}$ leak from SR. They proposed that RyR2 phosphorylation by protein kinase A caused FKBP12.6 dissociation and altered RyR2 gating [42], which is similar to the result induced by displacement from FKBP12.6 to FK-506 or rapamycin [56, 57]. However protein kinase A-mediated phosphorylation of RyR2 may not affect RyR2 activities in all animals [58]. Whereas, others, proposing that calmodulin modulation changing the gating properties of RyR2, thought the prevention of calmodulin binding to CaMBD in the RyR2 causes $\mathrm{Ca}^{2+}$ leak during the diastole process in heart failure $[44-47,59]$. The detailed mechanism is still not clear and requires additional study.

\section{The variation of key calcium handling proteins and the analysis of electrophysiological pathway data}

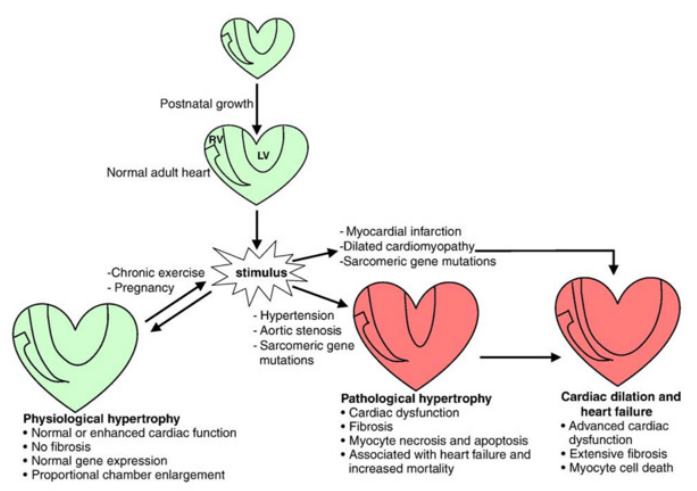

A

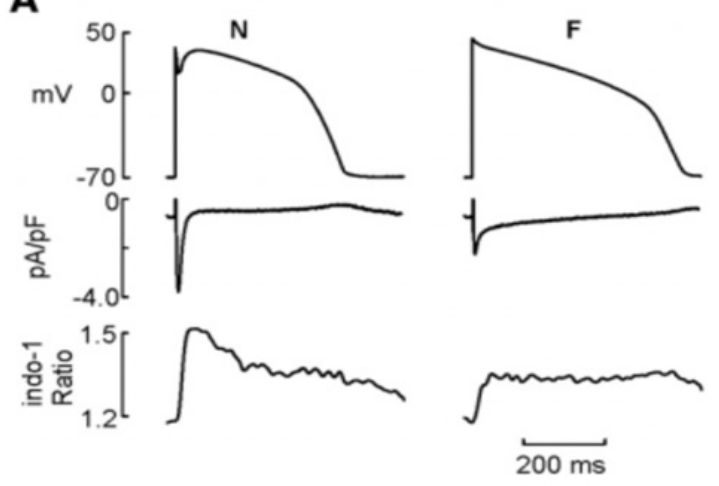

B

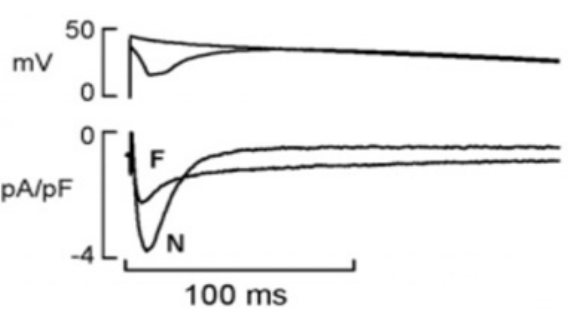

Figure 1. Physiological, pathological and heart failure ocuurs in diferent condition [60]. Physiological hypertrophy occurs during pregnancy or in response to chronic exercise training, is reversible and characterized by normal cardiac morphology and function. In contrast, pathological hypertrophy that occurs in settings of disease is detrimental for cardiac structure and function and can lead to heart failure. Developmental hypertrophy is associated with the normal growth of the heart after birth until adulthood. RV: right ventricle, LV: left ventricle. Normal/ physiological heart growth is shown in green, pathological heart growth is shown in red.

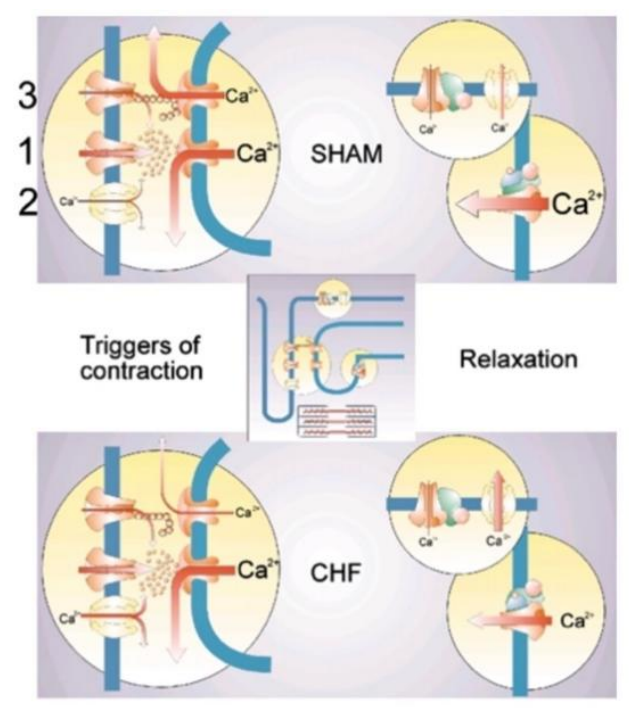

Figure 2. Human action potential (AP) waveform on E-C coupling(Cooper et al., 2010). (A) Huamn AP profiles of nonfailing $(\mathrm{N})$ and failing $(\mathrm{F})$ human myocytes (upper traces), and nifedipine sensitive ICa (middle traces), and indo1 fluorescence (lower traces). (B) Comparision of ICa notvh phase of the $\mathrm{N}$ and $\mathrm{F}$ Aps.

The main participants in the coupling between sarcolemma and SR are shown in Figure 3. They first include all L-type $\mathrm{Ca} 2+$ channels (No. 1), $\mathrm{N}_{\mathrm{a}}^{+}-\mathrm{Ca}^{2+}$ exchangers (No. 2), and possibly VSRM (No. 3). Since the $\mathrm{Na}+-\mathrm{Ca} 2+$ exchanger is up-regulated, the reduced 
gain is unlikely to be due to changes in the function of the protein. However, there may be multiple reasons why the L-type $\mathrm{Ca}^{2+}$ channel and RyR cannot communicate effectively. First, it is reported that the structure of the $\mathrm{T}$ tube changes during heart failure. Secondly, it has also been observed that the number of ryanodine receptors is reduced compared to L-type $\mathrm{Ca}^{2+}$ channels. Third, it has been proposed to increase the distance between the two proteins. Fourth, it is said that increased phosphorylation of lysine receptors can change EC coupling and cause basal $\mathrm{Ca}^{2+}$ leakage in SR.

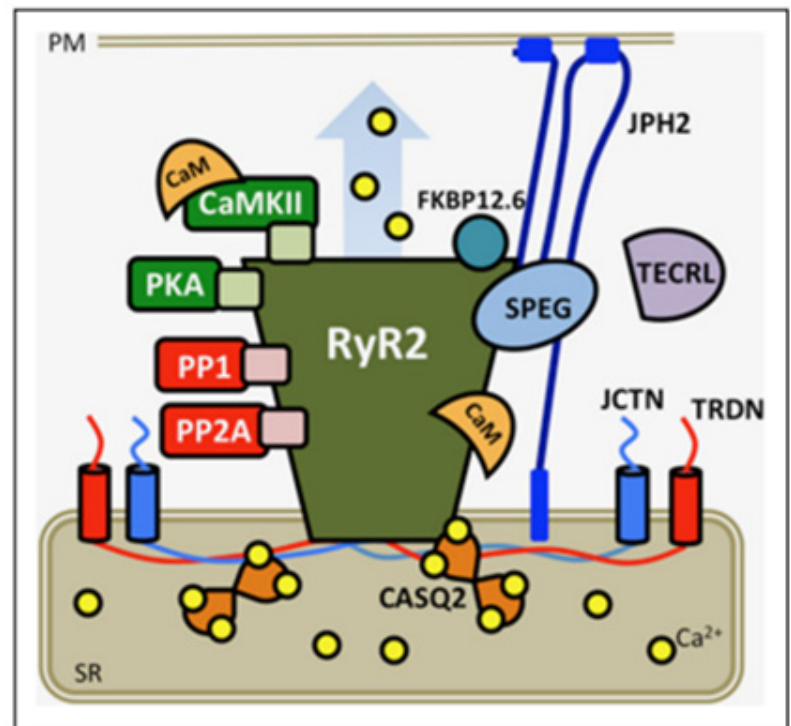

Figure 3. Illstration of alterations in excitation-contraction coupling in heart failure(Sjaastad et al., 2003) [61]. Cellular structures basis of calcium homeostasis are showed. Calcium release and uptake functions are altered in heart failure.

Each $\mathrm{Ca}^{2+}$ channel and transporter is composed of pore-forming proteins and various auxiliary subunits, which regulate the amount of $\mathrm{Ca}^{2+}$ that moves through the pore. These channels and switches have been extensively reviewed elsewhere. One of the most intensively studied multi-protein complexes may be the RyR2 macromolecular complex. Various RyR2 interacting proteins directly regulate RyR2 channel activity by binding to pore subunits.

Figure 4. Phosphorylation of Ryanodine receptor 2 [62]. CaM indicates calmodulin; CaMKII, $\mathrm{Ca}^{2+}$ calmodulin-dependent protein kinase II; CASQ2, calsequestrin-2; FKBP12.6, FK506binding protein- 12.6; JCTN, junctin; JPH2, juncophilin-2; PKA, protein kinase A; PM, plasma membrane; PP, protein phosphatase; SR, sarcoplasmic reticulum; TECRL, trans-2,3enoyl- CoA reductase-like protein; and TRDN; triadin.

\section{Conclusion}

In summary, L-type $\mathrm{Ca}^{2+}$ channel activity changed little during hypertrophy and heart failure, but a reduction in $\mathrm{Ca}^{2+}$ transient amplitude and kinetics triggered by current were found by comparing L-type $\mathrm{Ca}^{2+}$ channels in different models. In heart failure, desynchronized $\mathrm{Ca}^{2+}$ sparks slows the rate of $\mathrm{Ca}^{2+}$ transient rise, which may cause $\mathrm{Ca}^{2+}$ binding to troponin $\mathrm{C}$ to be disrupted and slow contraction of cardiomyocytes, and $\mathrm{Ca}^{2+}$ influx through L-type $\mathrm{Ca}^{2+}$ channels becomes ineffective upon triggering the release of $\mathrm{Ca}^{2+}$ from the RyR2. Scientists also found abnormal $\mathrm{Ca}^{2+}$ signaling between the surface membrane and the SR in heart failure. During the late stage of an action potential, the calcium current in failing cardiomyocytes is greater, mainly due to prolonged action potential duration triggering the antipattern of $\mathrm{Na}^{+}-\mathrm{Ca}^{2+}$ exchangers and reducing SR uptake.

\section{References}

1. Ballarino M, Cipriano A, Tita R, et al. Deficiency in the nuclear long noncoding rna charme causes myogenic defects and heart remodeling in mice. EMBO J, 2018, 37:

2. Ahuja P, Sdek P, MacLellan WR. Cardiac myocyte cell cycle control in development, disease, and regeneration. Physiological reviews, 2007, 87: 521544

3. Eisner DA, Caldwell JL, Kistamas $\mathrm{K}$, et al. Calcium and excitation-contraction coupling in the heart. Circ Res, 2017, 121: 181-195

4. Robinson P, Griffiths PJ, Watkins H, et al. Dilated and hypertrophic cardiomyopathy mutations in troponin and alpha-tropomyosin have opposing effects on the calcium affinity of cardiac thin filaments. Circ Res, 2007, 101: 1266-1273

5. Pinali C, Bennett H, Davenport JB, et al. Threedimensional reconstruction of cardiac sarcoplasmic reticulum reveals a continuous network linking transverse-tubules: This organization is perturbed in heart failure. Circ Res, 2013, 113: 1219-1230

6. Hayashi $\mathrm{T}$, Martone $\mathrm{ME}, \mathrm{Yu} \mathrm{Z}$, et al. Threedimensional electron microscopy reveals new details of membrane systems for ca $2+$ signaling in the heart. Journal of cell science, 2009, 122: 10051013

7. McNutt NS, Fawcett DW. The ultrastructure of the cat myocardium. Ii. Atrial muscle. The Journal of cell biology, 1969, 42: 46-67

8. Bridge JH. Relationships between the sarcoplasmic reticulum and sarcolemmal calcium transport revealed by rapidly cooling rabbit ventricular muscle. The Journal of general physiology, 1986, 88: 437-473

9. Negretti N, Varro A, Eisner DA. Estimate of net calcium fluxes and sarcoplasmic reticulum calcium content during systole in rat ventricular myocytes. The Journal of physiology, 1995, 486 ( Pt 3): 581591

10. Eisner DA, Trafford AW, Díaz ME, et al. The control of ca release from the cardiac sarcoplasmic reticulum: Regulation versus autoregulation. Cardiovascular research, 1998, 38: 589-604

11. Bernardo BC, Weeks KL, Pretorius L, et al. Molecular distinction between physiological and pathological cardiac hypertrophy: Experimental findings and therapeutic strategies. Pharmacology $\&$ therapeutics, 2010, 128: 191-227 
12. Davies $\mathrm{CH}$, Harding $\mathrm{SE}$, Poole-Wilson PA. Cellular mechanisms of contractile dysfunction in human heart failure. European heart journal, 1996, 17: $189-198$

13. Beuckelmann DJ, Näbauer M, Erdmann E. Intracellular calcium handling in isolated ventricular myocytes from patients with terminal heart failure. Circulation, 1992, 85: 1046-1055

14. Coraboeuf E, Nargeot J. Electrophysiology of human cardiac cells. Cardiovascular research, 1993, 27: $1713-1725$

15. Reuter H. The dependence of slow inward current in purkinje fibres on the extracellular calciumconcentration. The Journal of physiology, 1967, 192: 479-492

16. Bean BP. Classes of calcium channels in vertebrate cells. Annual review of physiology, 1989, 51: 367384

17. Chen CF, Hess P. Mechanism of gating of t-type calcium channels. The Journal of general physiology, 1990, 96: 603-630

18. Richard S, Leclercq F, Lemaire S, et al. Ca2+ currents in compensated hypertrophy and heart failure. Cardiovascular research, 1998, 37: 300-311

19. Nuss HB, Houser SR. T-type ca2+ current is expressed in hypertrophied adult feline left ventricular myocytes. Circ Res, 1993, 73: 777-782

20. Sen L, Smith TW. T-type ca2+ channels are abnormal in genetically determined cardiomyopathic hamster hearts. Circ Res, 1994, 75: 149-155

21. Momtaz A, Coulombe A, Richer P, et al. Action potential and plateau ionic currents in moderately and severely doca-salt hypertrophied rat hearts. Journal of molecular and cellular cardiology, 1996, 28: 2511-2522

22. Kääb S, Nuss HB, Chiamvimonvat $\mathrm{N}$, et al. Ionic mechanism of action potential prolongation in ventricular myocytes from dogs with pacinginduced heart failure. Circ Res, 1996, 78: 262-273

23. Scamps F, Mayoux E, Charlemagne D, et al. Calcium current in single cells isolated from normal and hypertrophied rat heart. Effects of betaadrenergic stimulation. Circ Res, 1990, 67: 199-208

24. Qin D, Zhang ZH, Caref EB, et al. Cellular and ionic basis of arrhythmias in postinfarction remodeled ventricular myocardium. Circ Res, 1996, 79: 461-473

25. Keung EC. Calcium current is increased in isolated adult myocytes from hypertrophied rat myocardium. Circ Res, 1989, 64: 753-763

26. Gómez AM, Valdivia HH, Cheng $\mathrm{H}$, et al. Defective excitation-contraction coupling in experimental cardiac hypertrophy and heart failure. Science (New York, NY), 1997, 276: 800-806

27. Dixon IM, Lee SL, Dhalla NS. Nitrendipine binding in congestive heart failure due to myocardial infarction. Circ Res, 1990, 66: 782-788
28. Mayoux E, Callens F, Swynghedauw B, et al. Adaptational process of the cardiac ca2+ channels to pressure overload: Biochemical and physiological properties of the dihydropyridine receptors in normal and hypertrophied rat hearts. Journal of cardiovascular pharmacology, 1988, 12: 390-396

29. Litwin SE, Zhang D, Bridge JH. Dyssynchronous $\mathrm{ca}(2+)$ sparks in myocytes from infarcted hearts. Circ Res, 2000, 87: 1040-1047

30. Sah R, Ramirez RJ, Backx PH. Modulation of ca2+release in cardiac myocytes by changes in repolarization rate. Circulation Research, 2002, 90: 165-173

31. Fabiato A. Time and calcium dependence of activation and inactivation of calcium-induced release of calcium from the sarcoplasmic reticulum of a skinned canine cardiac purkinje cell. The Journal of general physiology, 1985, 85: 247-289

32. Picht E, Zima AV, Shannon TR, et al. Dynamic calcium movement inside cardiac sarcoplasmic reticulum during release. Circulation Research, 2011, 108: 847-856

33. Wehrens $\mathrm{XH}$, Lehnart $\mathrm{SE}$, Reiken $\mathrm{S}$, et al. Ryanodine receptor/calcium release channel pka phosphorylation: A critical mediator of heart failure progression. Proc Natl Acad Sci U S A, 2006, 103: 511-518

34. Jiang MT, Lokuta AJ, Farrell EF, et al. Abnormal ca2+release, but normal ryanodine receptors, in canine and human heart failure. Circulation Research, 2002, 91: 1015-1022

35. Sipido KR, Stankovicova T, Flameng W, et al. Frequency dependence of ca2+ release from the sarcoplasmic reticulum in human ventricular myocytes from end-stage heart failure. Cardiovascular research, 1998, 37: 478-488

36. Mills GD, Harris DM, Chen X, et al. Intracellular sodium determines frequency-dependent alterations in contractility in hypertrophied feline ventricular myocytes. American journal of physiology Heart and circulatory physiology, 2007, 292: H1129-1138

37. Bassani JW, Yuan W, Bers DM. Fractional sr ca release is regulated by trigger ca and sr ca content in cardiac myocytes. The American journal of physiology, 1995, 268: C1313-1319

38. Bers DM, Eisner DA, Valdivia HH. Sarcoplasmic reticulum ca2+ and heart failure: Roles of diastolic leak and ca2+ transport. Circ Res, 2003, 93: 487490

39. Lyon AR, Bannister ML, Collins T, et al. Serca2a gene transfer decreases sarcoplasmic reticulum calcium leak and reduces ventricular arrhythmias in a model of chronic heart failure. Circulation: Arrhythmia and Electrophysiology, 2011, 4: 362372

40. Ikeda Y, Hoshijima M, Chien KR. Toward biologically targeted therapy of calcium cycling 
defects in heart failure. Physiology (Bethesda, Md), 2008, 23: 6-16

41. Meissner G. The structural basis of ryanodine receptor ion channel function. The Journal of general physiology, 2017, 149: 1065-1089

42. Marx SO, Reiken S, Hisamatsu Y, et al. Pka phosphorylation dissociates fkbp12.6 from the calcium release channel (ryanodine receptor). Cell, 2000, 101:

43. R MA, Steven R, O MS. Progression of heart failure: Is protein kinase a hyperphosphorylation of the ryanodine receptor a contributing factor? Circulation, 2002, 105:

44. Naohiro Y, Le X, A PD, et al. Molecular basis of calmodulin binding to cardiac muscle $\mathrm{ca}(2+)$ release channel (ryanodine receptor). The Journal of biological chemistry, 2003, 278:

45. P GJ, Noriaki I. Aberrant interaction of calmodulin with the ryanodine receptor develops hypertrophy in the neonatal cardiomyocyte. The Biochemical journal, 2011, 438:

46. G M, S HJ. Rapid calcium release from cardiac sarcoplasmic reticulum vesicles is dependent on ca2+ and is modulated by $\mathrm{mg} 2+$, adenine nucleotide, and calmodulin. The Journal of biological chemistry, 1987, 262:

47. R FB, M BJ, M BT, et al. Differential ca(2+) sensitivity of skeletal and cardiac muscle ryanodine receptors in the presence of calmodulin. American journal of physiology Cell physiology, 2000, 279:

48. E LS, T WXH, Steven R, et al. Phosphodiesterase $4 \mathrm{~d}$ deficiency in the ryanodine-receptor complex promotes heart failure and arrhythmias. Cell, 2005, 123:

49. Lehnart SE, Mongillo M, Bellinger A, et al. Leaky ca2+ release channel/ryanodine receptor 2 causes seizures and sudden cardiac death in mice. Journal of Clinical Investigation, 2008,

50. Heinzel FR, Bito V, Volders PGA, et al. Spatial and temporal inhomogeneities during ca2+ release from the sarcoplasmic reticulum in pig ventricular myocytes. Circulation Research, 2002, 91: 10231030

51. Cheng H, Lederer MR, Lederer WJ, et al. Calcium sparks and $[\mathrm{ca} 2+] \mathrm{i}$ waves in cardiac myocytes. The American journal of physiology, 1996, 270: C148159

52. Mironneau J, Arnaudeau S, Macrez-Lepretre N, et al. $\mathrm{Ca} 2+$ sparks and ca2+ waves activate different $\mathrm{ca}(2+)$-dependent ion channels in single myocytes from rat portal vein. Cell calcium, 1996, 20: 153160

53. Wehrens XH, Lehnart SE, Huang F, et al. Fkbp12.6 deficiency and defective calcium release channel (ryanodine receptor) function linked to exerciseinduced sudden cardiac death. Cell, 2003, 113: 829840
54. Neef S, Dybkova N, Sossalla S, et al. Camkiidependent diastolic sr ca2+ leak and elevated diastolic ca2+ levels in right atrial myocardium of patients with atrial fibrillation. Circ Res, 2010, 106: 1134-1144

55. Nattel S, Dobrev D. The multidimensional role of calcium in atrial fibrillation pathophysiology: Mechanistic insights and therapeutic opportunities. European heart journal, 2012, 33: 1870-1877

56. E K, R MA, E EB. Effects of rapamycin on ryanodine receptor/ca(2+)-release channels from cardiac muscle. Circulation research, 1996, 78:

57. P XR, H VH, K B, et al. The immunophilin fk506binding protein modulates ca2+ release channel closure in rat heart. The Journal of physiology, 1997, 500 ( Pt 2):

58. J P, R QF, L SG. Ca(2+)-handling proteins and heart failure: Novel molecular targets? Current medicinal chemistry, 2003, 10:

59. Jamille L, M dALV, C IM. Calcium handling proteins: Structure, function, and modulation by exercise. Heart failure reviews, 2014, 19:

60. C BB, L WK, Lynette $\mathrm{P}$, et al. Molecular distinction between physiological and pathological cardiac hypertrophy: Experimental findings and therapeutic strategies. Pharmacology \& therapeutics, 2010, 128:

61. Sjaastad I, Wasserstrom JA, Sejersted OM. Heart failure -- a challenge to our current concepts of excitation-contraction coupling. The Journal of physiology, 2003, 546: 33-47

62. P LA, Dobromir D, T WXH. Calcium signaling and cardiac arrhythmias. Circulation research, 2017, 120: 